\title{
Follow-up of 452 totally implantable vascular devices in cystic fibrosis patients
}

\author{
A. Munck*, S. Malbezin\#, J. Bloch`, M. Gerardin*, M. Lebourgeois*, J. Derelle ${ }^{+}$, F. Bremont ${ }^{\S}$, I. Sermet ${ }^{f}$, \\ M-R. Munck**, J. Navarro*
}

Follow-up of 452 totally implantable vascular devices in cystic fibrosis patients. A. Munck, S. Malbezin, J. Bloch, M. Gerardin, M. Lebourgeois, J. Derelle, F. Bremont, I. Sermet, M-R. Munck, J. Navarro. (C)ERS Journals Ltd 2004.

ABSTRACT: The use and complications of totally implantable vascular access devices (TIVADs) were examined during multiple courses of antibiotics in cystic fibrosis (CF) patients.

This retrospective study involved $36 \mathrm{CF}$ centres. Risk factors for removal and septicaemia were sought by survival analysis of censored data. Multivariate Cox models were constructed with removal or septicaemia as the event and the characteristics of TIVADs as explanatory variables.

TIVADs $(n=452)$ were implanted in 315 patients. The mean functional time per device was $32 \pm 25$ months. Long-term complications occurred with 188 devices $(42 \%)$; they consisted mainly of occlusion $(21 \%$, requiring removal in $77 \%)$, infection $(9.3 \%$, requiring removal in $85 \%$; septicaemia in $7.3 \%$; rate 0.3 per 1,000 days, Candida in $66 \%$ ), and vascular thrombosis $(4.7 \%$, removal in $58 \%)$. Multivariate survival analysis showed that removal, whatever the reason, was associated with polyurethane (versus silicone) and routine use of the device for blood sampling (versus never). No risk factors, including heparin lock, were identified for septicaemia or for removal for obstruction.

Totally implantable venous access devices appear to be safe and reliable for longterm intermittent venous access. Although retrospective, this study suggests that the characteristics of the material and blood sampling are risk factors for removal. Eur Respir J 2004; 23: 430-434.
Depts of *Paediatric Gastroenterology and Nutrition, ${ }^{\#}$ Anaesthesiology, and Public Health, Hospital Robert Debré, ${ }^{f}$ Dept of Paediatrics, Hospital Necker Enfants Malades, Paris, ${ }^{+}$Dept of Paediatrics, Nancy, ${ }^{8}$ Dept of Paediatrics, Toulouse, and **Dept of Paediatrics, Brest, France.

Correspondence: A. Munck

Hôpital Robert Debré

48 bd Sérurier

75019 Paris

France

Fax: 33140034755

E-mail: anne.munck@rdb.ap-hop-paris.fr

Keywords: Central venous access cystic fibrosis

intravenous antibiotic therapy

totally implantable vascular access devices

Received: May 122003

Accepted after revision: September 142003
Chronic infections in patients with cystic fibrosis $(\mathrm{CF})$, especially after colonisation by Pseudomonas aeruginosa, require repeated courses of intravenous antibiotics. Increasing problems with peripheral venous access may indicate implantation of a central venous access.

Relative to external central catheters, totally implantable vascular access devices (TIVADs) facilitate long-term maintenance, permit almost unlimited physical activity, and improve the patient's self-image, which is especially important for children and young adults. Nevertheless, TIVADs are associated with a number of complications. Previous studies of these devices in CF patients have involved small groups. The experience of $36 \mathrm{CF}$ centres over a period of $9 \mathrm{yrs}$ is reported here, based on systematic review of the implantation procedure, use, long-term maintenance and complications.

\section{Materials and methods}

\section{Patients}

The medical charts of $315 \mathrm{CF}$ patients who underwent one or more TIVAD procedures between January 1990 and December 1998 were reviewed. The patients were treated in 36 $\mathrm{CF}$ centres. A chart was sent to a corresponding physician in each CF centre who collected the data for all the patients treated in their centre. Data analysed included patient age, $P$. aeruginosa colonisation, surgical reports (TIVAD model, insertion site, procedure, prophylactic antibiotics, immediate complications), TIVAD use (courses of antibiotics, parenteral nutrition, lipid infusion, blood sampling), long-term maintenance (heparin, physiological sera, counter-pressure), longterm complications (catheter occlusion, vascular thrombosis, infection, discomfort, catheter rupture, displacement or disconnection, aesthetic prejudice, skin necrosis, pinch-off) and indications for TIVAD removal.

\section{Statistical analysis}

Univariate and multivariate analysis were performed using two separate models for censored data. Each device was considered as a statistical unit. The first model considered the life of the device and the withdrawal as the event, and assessed risk factors of withdrawal among explicative variables, such as the material of the device, long-term maintenance, and use of the device for blood sampling. The other model considered septicaemia as the event, withdrawal being a censure, with the same risk factor as the previous model. Significance level was 0.05 .

\section{Results}

Devices $(\mathrm{n}=452)$ were implanted in 315 patients with a mean age of $12.3 \pm 6.9$ yrs (range $0.42-43$ yrs) at the first implantation. $P$. aeruginosa colonisation was diagnosed in 418 patients 
(93\%). The mean interval between initial $P$. aeruginosa isolation and implantation of the first device was $49 \pm 0.4$ months (range 0-23.5 yrs).

\section{Surgical procedure}

Of the patients, $215(69 \%)$ received one device, $66(21 \%)$ received two, $27(9 \%)$ received three and six $(2 \%)$ received four. All the devices were inserted in the operating room. The procedure (427 available answers to the questionnaire (AAQ)) was performed by a surgeon in 263 cases $(62 \%)$, and by an anaesthetist in $164(38 \%)$. The insertion sites (440 AAQ) were mainly thoracic $(94 \%)$; only 26 devices $(6 \%)$ being implanted brachially. The vascular access was prepared by denudation in one-half of the cases and percutaneously in the other half. The main sites of cannulation (408 AAQ) were the internal jugular vein in 141 cases $(35 \%)$, the subclavian vein in 137 $(34 \%)$, the external jugular vein in $94(23 \%)$, the cephalic vein in $20(5 \%)$, the basilic vein in $10(2 \%)$ and the humeral vein in four $(1 \%)$. The right side of the body was used for $69 \%$ of the devices.

A large variety of models were used in the different centres: the catheter material (289 AAQ) was silicone in 201 cases $(70 \%)$ and polyurethane in $88(30 \%)$; the catheter diameter (193 AAQ) was mainly 5, 6 or 7 French $(26,30$ and $38 \%$ of cases, respectively); port sizes (203 AAQ) were micro in 65 cases $(32 \%)$, paediatric in 76 cases $(37 \%)$ and adult in 62 cases (31\%). At the time of insertion (401 AAQ), 269 patients $(67 \%)$ were on intensive intravenous antibiotic therapy for pulmonary exacerbations and 60 were receiving prophylactic antibiotics (357 AAQ), mainly consisting of aminoglycosides (40\%), vancomycin $(26 \%)$, amino penicillin $(6 \%)$ and cephalosporins $(4 \%)$.

\section{Immediate complications}

Immediate complications (452 AAQ) occurred in 17 cases $(4 \%)$, with eight cases of haematoma $(1.8 \%)$, four pneumothoraces $(0.9 \%)$, one haemothorax, one minor wound to the external jugular vein, one case of abdominal pain, one of local redness, and one of severe bronchospasm. No association was found between the occurrence of immediate complications and the type of vascular access.

\section{Totally implantable venous access device use}

The devices were used chiefly (432 AAQ) for intermittent antibiotic infusion (86\%); 14\% were used for regular parenteral nutrition or lipid infusion. Blood sampling (407 AAQ) was performed through the devices routinely in 56 cases $(14 \%)$, occasionally in $171(42 \%)$ and never in 180 (44\%). Anaesthetic cream was applied to the skin before insertion of the Huber needle (421 AAQ) in 49\% of TIVADs.

\section{Long-term maintenance}

The TIVAD maintenance protocol (432 AAQ) consisted of flushing with heparin solution in 385 cases $(89 \%)$ every $3.9 \pm 1.7$ weeks, flushing with physiological saline in 25 cases $(6 \%)$ and a counter-pressure technique in 87 cases $(20 \%)$.

\section{Totally implantable venous access device lifespan}

The mean functional time per device (449 AAQ) was $32 \pm 25$ months, and ranged from $0-165$ months $(1,205$ catheter-yrs).
The mean number of antibiotic courses per device was $8.4 \pm 6.4(0-32)$.

\section{Long-term complications}

Late complications (452 AAQ) occurred in 188 cases $(42 \%$; table 1). Catheter occlusion was the most common mechanical complication, occurring in $21 \%$ of cases and requiring removal of the device in $77 \%$.

Infectious complications $(8.6 \%)$ included septicaemia and site infection, and led to removal of the catheter in $83 \%$ of relevant cases. The mean duration of catheter residence prior to infection was $680 \pm 546$ days. Catheter-related septicaemia occurred with $7.3 \%$ of devices ( 0.3 per 1,000 catheter-days). Organisms cultured from blood or the device were fungi (66\%), Staphylococcus epidermidis $(22 \%)$, S. aureus $(6 \%)$ and Gram-negative bacilli $(6 \%) ; P$. aeruginosa was never isolated. The device was always removed when fungaemia occurred. There were eight episodes of site infection (1.3\%) requiring removal of the device in $83 \%$ of relevant cases. The TIVADs were mainly used for intermittent antibiotic infusion, although lipid infusion or parenteral nutrition was combined in $14 \%$. No association was found between total parenteral nutrition (TPN) and the risk of septicaemia. Multivariate analysis identified no risk factors associated with the risk of septicaemia, including the catheter material, site of insertion, long-term maintenance, blood sampling and parenteral nutrition.

Vascular thrombosis occurred with 21 TIVADs (4.7\%); medical therapy was ineffective in $57 \%$, requiring removal of the device. In this study, the catheter was made of silicone in $70 \%$ of cases and polyurethane in $30 \%$. An association was found between the risk of vascular thrombosis and the use of polyurethane $(11.4 \%)$ versus silicone $(1.5 \%$; $p<0.01$, Chisquared test) and between the risk of vascular thrombosis and the site of TIVAD insertion (brachial 20\% versus thoracic $3.6 \% ; \mathrm{p}<0.01)$. With brachial devices, the main sites of vein cannulation were humoral, basilic and cephalic; this may explain the high rate of thrombosis.

Frequent complications ( $<5 \%$ of cases) included discomfort in $4.4 \%$ (requiring replacement in $15 \%$ ), catheter displacement in $3 \%$ (requiring removal in $92 \%$ ), catheter disinsertion in $2 \%$, and catheter rupture in $2 \%$ (all required removal), skin necrosis in $1 \%$ (requiring removal in $80 \%$ ), aesthetic prejudice in $1 \%$ (requiring removal in $20 \%$ ) and pinch-off in $0.4 \%$ (never requiring removal).

\section{Totally implantable venous access device removal}

Of the $452(37 \%)$ devices, 170 were removed, generally for complications (table 2) comprising 72 catheter occlusions

Table 1.-Main long-term complications and removal of the device

$\begin{array}{cc}\begin{array}{c}\text { Complications } \\ \%\end{array} & \begin{array}{c}\text { Removal of } \\ \text { the device } \%\end{array} \\ 21 & 77 \\ 8.6 & 83 \\ 4.7 & 57 \\ 4.4 & 15 \\ 3 & 92 \\ 2 & 100 \\ 2 & 100 \\ 1 & 80 \\ 1 & 20 \\ 0.4 & 0 \\ \end{array}$


Table 2.-Main indications for the 170 totally implantable venous access device removal

Catheter occlusion 43

Infection

Vascular displacement

Catheter disinsertion

Catheter rupture

Transplantation

Clinical improvment

Skin necrosis

Others: discomfort, aesthetic prejudice, short-length catheter

Data are presented as per cent.

(43\%), 36 infections $(21 \%), 12$ vascular thromboses $(7 \%), 11$ catheter displacements $(6.5 \%), 10$ catheter disinsertions $(6 \%)$, nine catheter ruptures $(5 \%)$, four cases of skin necrosis $(2.5 \%)$ and three of discomfort $(2 \%)$, two short-length catheters $(1 \%)$ and one for aesthetic prejudice. In the present study, multivariate survival analysis (Cox models) showed that blood sampling via the TIVAD carried a relative risk of 2.23 (95\% confidence interval $(\mathrm{CI}) 1.244 .01$; $\mathrm{p}<0.01)$ for device removal for all reasons versus nonuse. Furthermore, multivariate analysis (Cox models) showed that polyurethane devices were twice as likely as silicone devices to be removed, whatever the reason (relative risk 2, 95\% CI 2.05-161.7; $\mathrm{p}<0.01)$. The device was also removed from six patients $(4 \%)$ undergoing lung transplantation, owing to the risk of infection associated with long-term immunosuppression and from four patients $(2.5 \%)$ with clinical improvement, allowing intravenous antibiotic therapy to be stopped.

\section{Discussion}

Experience with long-term TIVAD implantation in patients with CF is still limited, but these devices are commonly used in the management of patients with cancer and acquired immune deficiency syndrome (AIDS). The use of TIVADs in patients with CF was first described in 1986 by PATTISON and HEAF [1]. Since then, only a few retrospective studies have been published, involving cohorts of between nine [2] and 115 [3] children or adults, with follow-up ranging from 2-13 yrs. A summary of previous studies in CF patients [3-12] is presented in table 3 . The multicentre retrospective study over 9 yrs is the largest to date, with 1,205 catheter-yrs. The medical charts of 315 patients treated from January 1990 to December 1998 in 36 CF centres were reviewed.

The mean age at insertion of the first device was younger here than in most other studies [2-10] but similar to that in the study by DeERoJANAwong et al. [11] and older than in the series of CASSEY et al. [12]. Most of the patients had the devices inserted while on intensive intravenous therapy for pulmonary infection or antibiotic prophylaxis. Only one previous study, involving heterogeneous patients, mentioned antibiotic prophylaxis lasting 7 days in $\mathrm{CF}$ patients [13].

In contrast with most reports [3-5, 7-10, 13], the devices in the present study were not exclusively inserted by a surgeon but by an anaesthetist in $38 \%$ of cases. The vascular access was created by denudation for one-half of the devices and percutaneously for the others; this procedure is less traumatic for the vein but may be associated with an increased rate of pneumothorax when the subclavian vein is chosen [2]. In this study, the subclavian vein was cannulated in only $34 \%$ of cases, and severe immediate complications such as pneumothorax were rare compared with the $3.5 \%$ reported by AITKEN and TONELli [4] or $4.4 \%$ by MORRIS et al. [5], reaching $9.2 \%$ reported by BURDON et al. [10]. In these studies, the subclavian vein was frequently catheterised (78, 82 and $100 \%$, respectively) and this may explain the high rate of complications. However, it is interesting to note that the present authors had a very low incidence of pneumothorax, even with a percutaneous access.

Mechanical problems such as catheter occlusion were the most common complications in the study, with a rate of $21 \%$, similar to that reported by DEEROJANAWONG et al. [11]; catheter removal was necessary in $77 \%$ in the present study and $53 \%$ of cases in the last study. The salvage rate of blocked catheters with urokinase was low $(23 \%)$ compared with the 96\% reported by MORRIS et al. [5], possibly owing to early intervention. Patients should be warned to seek medical advice if their TIVAD becomes slow to flush.

Vascular thrombosis occurred with $4.7 \%$ of TIVADs in this study, a rate lower than the $9 \%$ in the study by DEEROJANAWONG et al. [11]; removal was necessary for $57 \%$ and $100 \%$ of the catheters, respectively. PECKHAM et al. [14] reported the efficacy and safety of thrombolytic therapy, but this point remains controversial. No cases of thromboembolism related to the device were identified in the present study, but this complication has been described by others [15]. DeERojanawong et al. [11] recommends Doppler ultrasonography to detect unsuspected thrombosis, allowing early thrombolytic treatment. In order to reduce the high incidence of mechanical complications, SolA et al. [7] recommended prophylactic use of aspirin by all CF patients free of liver disease and clotting disorders, but there are too few data to support this recommendation. Furthermore, the risk of haemoptysis remains a particular concern in patients with $\mathrm{CF}$.

Table 3. - Summary of case series of totally implantable venous access device (TIVAD) complications in patients with cystic fibrosis

\begin{tabular}{|c|c|c|c|c|c|c|c|c|}
\hline Source and year & $\begin{array}{l}\text { Patients } \mathrm{n} / \\
\text { TIVAD } \mathrm{n}\end{array}$ & Catheter-yrs & Pneumothorax & $\begin{array}{l}\text { Catheter } \\
\text { occlusion }\end{array}$ & Infection & Thrombosis & $\begin{array}{l}\text { Mechanical } \\
\text { complication }\end{array}$ & Overall \\
\hline Current study 2004 & $315 / 452$ & 1205 & 0.9 & 21 & 8.6 & 4.7 & & 42 \\
\hline [3] 2000 & $74 / 115$ & & 1.4 & & 14 & 3.5 & 36 & 54 \\
\hline [4] 2000 & $65 / 87$ & 210 & 3.5 & 7 & 10.5 & 16 & & 40 \\
\hline [5] 1990 & $58 / 68$ & 73 & 4.4 & 34 & 17.6 & & & \\
\hline [6] 1989 & $26 / 26$ & 29 & & & 8.7 & 4 & 27 & 40 \\
\hline [7] 1992 & $15 / 22$ & 36 & & 14 & 9 & 14 & 27 & 36 \\
\hline [8] 1996 & $18 / 33$ & 71 & 0 & 66 & 15 & 10 & & \\
\hline [9] 1998 & $42 / 61$ & 269 & 1.6 & 16 & 5 & 6.5 & & 38 \\
\hline [10] 1998 & $57 / 65$ & 78 & 9 & & 8 & & & 32 \\
\hline [11] 1998 & $44 / 57$ & 145 & & 22 & 31 & 9 & 53 & 84 \\
\hline [12] 1988 & $13 / 15$ & 17 & & 6.6 & 0 & & 13 & 20 \\
\hline
\end{tabular}

Data are presented as per cent of devices unless otherwise stated. 
It would be of interest to manage a large scale prospective study evaluating factors favouring thrombosis before the insertion of central venous catheters.

In this study, long-term maintenance of TIVADs, when not in use, was based mainly on heparin; this seems to be the standard method for maintaining line patency [5-8, 10-13]. Counterpressure was used by ESSEX-CATER et al. [13] and BURDON et al. [10], and in $20 \%$ of cases in the present series. To date, there is no standard maintenance therapy, and randomised prospective studies would be of great interest.

The TIVADs in this study were used mainly for intermittent antibiotic infusion, although lipid or parenteral nutrition was combined in $14 \%$. In other series, nutritional support was combined routinely [7], or for one-half of the devices [2] or for $31 \%$ [5], with no increase in the risk of infection. However, in the study by BURDON et al. [10], the two patients with Candida septicaemia were receiving nutritional support; the author recommended that TPN should only be given through the port if essential for the patient. The study by ALLEN et al. [16], which involved $25 \mathrm{CF}$ patients, showed an increased rate of central venous catheterrelated sepsis (1.29 to 3.45 cases per 1,000 days) during TPN.

Large differences in blood sampling practices are found among studies; the TIVAD being used systematically in the series by DEEROJANAWONG et al. [11], rarely in the study by YUNG et al. [8] and never in the studies by CASSEY et al. [12] or KARIYAWASAM et al. [3]. Since the authors have shown that blood sampling via TIVAD carries a higher risk for device removal, the medical team must be aware of the choice between a better comfort for the patient or a longer TIVAD lifespan.

Catheter-related septicaemia was reported by MorRIs et al. [5] (10\% rate over 4 yrs), DEEROJANAWONG et al. [11] $(9.1 \%$ over 9 yrs), RoDGERs et al. [9] (5\%) and YUNG et al. [8] (9.6\% over 8 yrs), while CASSEY et al. [12] and STEAD et al. [2] reported no cases of bacterial or fungal sepsis in these two short follow-up studies. The $7.3 \%$ rate of septicaemia over $9 \mathrm{yrs}$ in this study is relatively low. SolA et al. [7] and DEEROJANAWONG et al. [11] identified certain factors potentially increasing the infection rate, including corticosteroid therapy, parenteral nutrition, diabetes mellitus, malnutrition, severe respiratory deficiency, and frequent broad-spectrum antibiotic therapy. A high incidence of fungal septicaemia (66\% in this study) occurs among CF patients [17, 18]. Whether or not CF patients with TIVADs should receive daily antifungal prophylaxis is controversial [8, 18, 19].

LA QuAGLia et al. [20] identified the age of $<7$ yrs as a significant predictor of device-related septicaemia. Ross et al. [21] found that prematurity, parenteral nutrition and continuous catheter use, but not the duration of catheter residence, increased the risk of thrombosis. The retrospective multicentre study shown did not permit the analysis of this many parameters.

The rate of complications in $\mathrm{CF}$ patients compares favourably to other populations studied. The occurrence of thrombosis in the present patients was lower than the one reported in patients with malignant disease $[22,23]$ or sickle cell disease [24]. A higher rate of infectious complications has been described in oncology patients [23, 25], AIDS [26] or in sickle cell disease [24]. Furthermore, it should be mentioned that because of disease-related mortality (cancer, AIDS), TIVADs used in these patients have less time in situ to develop complications. Complications more likely to occur in $\mathrm{CF}$ patients have not been identified.

In this study the overall rate of complications was $42 \%$, a rate higher than in other series $(20-38 \%)$ with shorter follow-up [7, 9, 10, 12], but lower than that reported by DeErojanawong et al. [11] (84\% over $9 \mathrm{yrs})$ and KARIYAWASAM et al. [3] (54\% over 13 yrs).
In this study the mean functional life per device is a little better than in other studies, DeErojanawong et al. [11] reporting a median of 690 days, MORRIS et al. [5] 458 days, SolA et al. [7] 539 days, and STEAD et al. [2] 180 days. The median port lifetime was 53 months in RoDGERs study [9], and 45 months in the series by KARIYAWASAM et al. [3]. YUNG et al. [8] found a huge difference between the median survival of Port-a-Cath (1,146 days; Celsite B. Braun Biotrol S.A., Paris, France) and P.A.S. Port devices (248 days; Graseby Medical Ltd, Walford, UK).

This study shows that totally implantable vascular access devices are relatively safe and reliable long-term intermittent venous accesses for cystic fibrosis patients who require frequent intravenous antibiotic therapy. There are, however, major risks associated with totally implantable vascular access devices, and patients should be carefully selected. The catheter material and blood sampling were risk factors for removal, and the insertion site significantly influenced the occurrence of vascular thrombosis. No risk factors for septicaemia were identified.

\begin{abstract}
Acknowledgements. The authors would like to thank the following investigators for the essential part they played in the enrolment of patients: I. Durieu, G. Bellon (Lyon), D. Hubert (Paris), E. de Neuville (Rennes), D. Druon (Montreuil sur Mer), C. Giraut (Tours), N. Wizla, M. Scalbert (Lille), J.F. Lesure (La Réunion), V. David (Nantes), A. Loeuille (Dunkerque), E. Duveau (Angers), H. Laselve (Roscoff), B. Leluyer (Le Havre), J.G. Pautard (Amiens), F. Huet (Dijon), L. de Lumley (Limoges), V. Storni (Roscoff), O. Mouterde (Rouen), A. Sardet (Lens), M.L. Dalphin (Besançon), I. Pin (Grenoble), G. Picherot (Saint Nazaire), M. Dagorne (Saint Brieuc), M.C. Heraud (Clermont Ferrand), M. Guillot (Lisieux), K. Lashinat (Elbeuf), R. Barnier (Dieulefit), P. Gautry (Brive), and M. Albertoni (Nice).
\end{abstract}

\section{References}

1. Pattison J, Heaf DP. Totally implantable vascular access in treatment of cystic fibrosis. Lancet 1986; i: 799.

2. Stead RJ, Davidson TI, Duncan FR, Hodson M, Batten JC. Use of a totally implantable system for venous access in cystic fibrosis. Thorax 1987; 42: 149-150.

3. Kariyawasam HH, Pepper JR, Hodson ME, Geddes DM. Experience of totally implantable venous access devices (TIVADs) in adults with cystic fibrosis over a 13-year period. Respir Med 2000; 94: 1161-1165.

4. Aitken ML, Tonelli MR. Complications of indwelling catheters in cystic fibrosis. A 10 year-review. Chest 2000; 118: 1598-1602.

5. Morris JB, Occhionero ME, Gauderer MWL, Stern RC, Doershuk CF. Totally implantable vascular access devices in cystic fibrosis: a four-year experience with fifty-eight patients. J Pediatr 1990; 117: 82-85.

6. Ball AB, Duncan FR, Foster FJ, Davidson TI, Watkins RM, Hodson ME. Long term venous access using a totally implantable drug delivery system in patients with cystic fibrosis and bronchiectasis. Respir Med 1989; 83: 429-431.

7. Sola JE, Stone MM, Wise B, Colombani P. Atypical thrombotic and septic complications of totally implantable venous access devices in patients with cystic fibrosis. Pediatr Pulmonol 1992; 14: 239-242.

8. Yung B, Campbell JA, Elborn JS, Harvey JS, Shale DJ. Totally implantable venous access devices in adult patients with cystic fibrosis. Respir Med 1996; 90: 353-356. 
9. Rodgers HC, Liddle K, Nixon SJ, Innes JA, Greening AP. Totally implantable venous access devices in cystic fibrosis: complications and patients opinions. Eur Respir J 1998; 12: 217-220.

10. Burdon J, Conway SP, Murchan P, Lansdown M, Kester RCK. Five years' experience of PAS port intravenous access system in adult cystic fibrosis. Eur Respir $J$ 1998; 12: 212-216.

11. Deerojanawong J, Sawyer SM, Fink AM, Stokes KB, Robertson CF. Totally implantable venous access devices in children with cystic fibrosis: incidence and type of complications. Thorax 1998; 53: 285-289.

12. Cassey J, Ford WDA, O'Brien LO, Martin AJ. Totally implantable system for venous access in children with cystic fibrosis. Clin Pediatr 1988; 27: 91-95.

13. Essex-Cater A, Gilbert J, Robinson T. Littlewood JM. Totally implantable venous access systems in paediatric practice. Arch Dis Child 1989; 64: 119-123.

14. Peckham DG, Hill J, Manhire AR, Knox AJ. 1. Resolution of superior vena cava obstruction following thrombolytic therapy in a patient with cystic fibrosis and a long-term indwelling catheter. Respir Med 1994; 88: 627-629.

15. Yung B, Elborn JS, Campbell IA, Summers Y, Beckles M, Woodcock AA. Thromboembolism related to a Port-a-Cath device in a patient with cystic fibrosis. Thorax 1997; 52: 98 99.

16. Allen ED, Mick AB, Nicol J, McCoy K. Prolonged parenteral nutrition for cystic fibrosis patients. Nutr Clin Pract 1995; 10: 73-79.

17. Bonacorsi $\mathrm{S}$, Munck $\mathrm{A}$, Ovetchkine $\mathrm{P}$, et al. In situ management and molecular analysis of candidemia related to a totally implantable vascular access in a cystic fibrosis patient. J Infect 1996; 93: 49-51.

18. Horn CK, Conway SP. Candidaemia: risk factors in patients with cystic fibrosis who have totally implantable venous access systems. J Infect 1993; 26: 127-132.

19. Fahy JV, Keoghan MT, Crummy EJ, Fitzgerald MX Bacteraemia and fungaemia in adults with cystic fibrosis. J Infect 1991; 22: 241-245.

20. La Quaglia MP, Lucas A, Thaler HT, et al. A prospective analysis of vascular access device-related infections in children. J Pediatr Surg 1992; 27: 840-842.

21. Ross P, Ehrenkranz R, Kleinman CS, et al. Thrombus associated with central venous catheters in infants and children. J Pediatr Surg 1989; 24: 253-256.

22. Brothers TE, Von Moll LK, Niederhuber JE, et al. Experience with subcutaneous infusion ports on 300 patients. Gynecol Obstet 1988; 166: 295-301.

23. Biffi R, de Braud F, Orsi F, et al. Totally implantable central venous access ports for long-term chemotherapy: a prospective study analyzing complications and costs of 333 devices with a minimum follow-up of 180 days. Annal Oncol 1998; 9: 767-773.

24. Abdul-Rauf A, Gauderer M, Chiarucci K, et al. Long-term central venous access in patients with sickle cell disease. J Pediatr Hematol Oncol 1995; 17: 342-345.

25. Wurzal CL, Halon K, Feldman JG, et al. Infection rates of Broviac-Hickman catheters and implantable venous devices. Am J Dis Child 1988; 142: 536-540.

26. Goodman HE, Brettle RP, Stevenson B, et al. Central venous catheters in patients with AIDS. Int $J$ STD AIDS 1997; 8: 417-422. 